\title{
Antifungal Resistance and its Evolution: An Increasing Concern
}

\author{
Claudia Ortiz ${ }^{1 *}$ and Rodrigo Torres ${ }^{2}$ \\ ${ }^{1}$ School of Microbiology, Universidad Industrial de Santander, Colombia \\ ${ }^{2}$ Laboratory of Biotechnology, Instituto Colombiano del Petroleo, Colombia
}

Submission: May 26, 2018; Published: August 07, 2018

*Corresponding author: Claudia Ortiz, School of Microbiology, Faculatd de Salud, Universidad Industrial de Santander, Bucaramanga, Colombia; Tell: 3164363960; Email: ortizc@uis.edu.co

\begin{abstract}
This work describes different mechanism of drug resistance and some aspects of evolution of fungi in order to evade antifungal effects. Fungal infections are an issue of concern, and it is necessary to develop new strategies in order to mitigate mortality rates caused by these types of pathogens. However, fungi exhibit different resistance mechanisms, ranging from genetic mutations to metabolic adaptations to the action of several antifungal compounds available for clinical treatments. However, some antifungal resistance are no-evident and need to be studied in order to avoid rising of new resistant fungal strains. Moreover, it is well known that drug resistance is linked to fungal evolution. For this reason, it is important to understand adaptation mechanisms carried out by fungi to resist antibiotic action, such as aminoacid mutations or different metabolic responses of fungal species to several antifungal drugs, in order to, design both new antifungal compounds or strategies for treating fungal infections.
\end{abstract}

Keywords: Antifungal resistance; Antifungals; Evolution; Fungal infections; Drugs; Pathogens; metabolic Adaptations; Aspergillus species; C. guillermondii; C. lusitaniae; C. parapsilosis; Fluconazole; Fusarium; Enzyme; Toxicity; Phenomenon; C. glabrata; Candida species; Biofilms; Multi drug resistant microorganisms; Inhibitory

Abbreviations: MDR: Multi Drug Resistant Microorganisms; MIC: Minimum Inhibitory Concentration

\section{Mini Review}

\section{Antifungal resistance}

Over the past 30 years, the importance of antifungal drugs to the practice of modern medicine has increased dramatically. Antifungal drugs used for therapy of fungal diseases can lead to antifungal resistance. Based on a study conducted by National Institute of Health, in the United States during 1980-1997, mortality rates due to invasive mycoses have been increased by 3.2 fold [1,2]. In addition, high both mortality and morbidity caused by poor diagnosis, emergence of drug-resistance and lack of effective antifungal therapy are commonly produced [2]. Nevertheless, antifungal resistance has been described for all virtually antifungal agents in several pathogens, including Candida and Aspergillus species. Additionally, azole resistance in A. fumigatus is widespread with high geographic variance since the first report of itraconazole resistance in 1997 [3]. Moreover, Candida genera exhibit resistance against almost all antifungals available, especially against Fluconazole [4-7]. For instance, C. lusitaniae and C. guillermondii are intrinsically resistant to amphotericin B [8], while other ones such as C. glabrata or C. parapsilosis are more resistant to echinocandins $[3,9]$. More alarming are the recent global epidemics of C. auris, which displays high resistance to all classes of antifungal drugs, eliminating effective therapeutic options [10,11]. Similarly, resistance in molds against antifungals available in the market has been demonstrated by Aspergillus fumigatus and other Aspergillus species, and even genera as Scedosporium and Fusarium [12]. For example, A. flavus and A. terreus are able to tolerate higher concentrations of amphotericin B compared to other Aspergillus species, due to different response to oxidative stress $[13,14]$.

In addition, some species of Cryptococcus, which are responsible for more than 1 million infections at high mortality rates (620 thousand deaths per year in sub-Saharan Africa), are resistant to echinocandins, limiting the options of treatment of polyenes that target ergosterol or its biosynthesis $[15,16]$. Mechanisms of antifungal resistance have been elucidated at molecular level for most of antifungal agents and fungal pathogens. However, molecular mechanisms that lead to antifungal resistance are very complex. These mechanisms include: decrease in effective drug concentration, alteration of drug targets, and metabolic "by pass" [3, 7, 17-20].

Decreasing of effective drug concentrations can be achieved by: Modification of diffusion mechanisms, mediated by the activity of several efflux transport, and, overexpression of the 
targeted protein by modification of the promoter region of the gene, which increases drug resistance, offering a pathway for adaptive evolution and a tool for target identification. Overexpression of ERG11 has also been reported for azoleresistant in isolates of C. glabrata, Candida parapsilosis, Candida tropicalis, and Candida krusei. However, the mechanism for this overexpression or its contribution to azole resistance in these species remains largely unknown [19]. Another mechanism of resistance, generally involved in the reducing of drug uptake, is the biofilm formation, associated with resistance to several drugs, including azoles, polyenes, and pyrimidine analogs [7].

These different mechanisms, which may be responsible for the intrinsic resistance of Candida species biofilms, include high density of sessile cells, growth and nutrient limitation, effects of the biofilm matrix, presence of persistent cells, antifungal resistance gene expression and increase of sterols on the membrane of biofilm cells [21-23]. Recent data showed that the cell matrix is involved in this process due to its ability to capture and store antifungal agents. This process has been clearly documented for fluconazole $[22,24]$ and suggested for AmB in C. albicans [25].

Genetic modification of the drug target resulting in reduced affinity for drug is one of the most prominent mechanisms for antifungal resistance $[3,20]$. Several studies describe point mutations in the ERG11 (CYP51) gene, which encodes 14- $\alpha$-demethylase; and these amino acid substitutions alter protein structure, decreasing enzyme affinity for azole with the consequent impact of fungal susceptibility to fluconazole. A single instance of an ERG11 mutation has been reported in C. glabrata; a clinical isolate containing a missense mutation produced a cell membrane with no-ergosterol and displayed high resistance to fluconazole [26]. Alteration drug target has been reported for at least two classes of antifungal agents, including azoles and echinocandins. The targets of these two drugs are 14-alpha-demethyliase and Beta-1,3-glucan synthase, respectively. Lanosterol demethylase is encoded by ERG11 in C. albicans and Cyp51A in A. fumigatus. Mutations in ERG11 producing non-synonymous substitutions of amino acids that are present in isolates of $\mathrm{C}$. albicans resistant to azoles. These are numerous and show decrease in affinity of the target to antifungal azoles [27].

Metabolic By-pass occurs when the metabolic pathways are disturbed by loss or sharp decrease in specific cell functions. The metabolic by-pass can be compared with compensatory mechanisms in which the cells by-pass toxic effects exerted by some antifungal agents. For example, azole resistance can be measured by loss of function mutations in the ERG3 gene encoding a sterol $\Delta 5,6$-desaturase. If this gene is activated, the enzyme expressed converts 14-alpha-methylated sterols that arise from exposure to azoles into a toxic 3,6-diol derivative [28]. Fungi that are unable to produce this metabolite have azole resistance. Several studies have been reported of mutations that produce the loss of function of ERG3 and exhibit azole resistance [29-32]. However, due to a deficiency in ergosterol biosynthesis, these isolates may be less competitive than wild-type isolates under conditions found in the host. As a result of the loss of function of ERG3 in specific mutants, ergosterol is absent from cell membranes. In this way, mutants evade the toxic effect of AmB, which normally acts as a "sponge" for ergosterol to rapidly destabilize membrane functions [33]. Other mutations in the ergosterol biosynthesis pathway (ERG6, ERG24, and ERG2) lead to the same effect and also have a compensatory effect [34-36]. A mutation in the FUR1 gene that uracil phosphoribosyl transferase decreases the conversion of 5-Fluoro-Uracyl (5-FU), which is produced from the deamination of 5-Fluoro-Cytosyne(5-FC), in a toxic metabolite (5-FC- monophosphate). In this way, the toxic effect of 5-FC cannot be exerted [37].

\section{Evolution of antifungal resistance}

Evolution of resistance to antifungal drugs is of particular interest due to the increasing incidence of fungal infections that threaten health of patients and limited number of antifungal drugs with different targets [38]. During this transformation, microorganisms have adapted to compete and survive in their natural environments $[39,40]$. At the species level, fungi may differ in their inherent ability to proliferate during stress induced by drug exposure, regardless of the acquisition of specific adaptive mutations, which is often referred to as tolerance $[38,41,42]$. At the population level, fungi can acquire specific mutations that reduce the inhibitory effects of a drug, creating resistance.

Frequency of which resistance is acquired varies dramatically depending on the type of antifungal used. In the case of resistance to azoles, this is the most prevalent, due to both fungistatic nature and strong selection pressure exerted on the survivor populations $[42,43]$. For echinocandins, a specific type of tolerance denominated paradoxical effect is observed, so that the fungal growth is restored at drug concentrations substantially that are higher than the Minimum Inhibitory Concentration (MIC) $[44,45]$. This mechanism is due in part to the transcriptional overregulation of the chitin synthases in A. fumigatus and C. albicans, once they are exposed to the echinocandins [44], facilitating mutations that confer fungal resistance.

Variations of susceptibility to antifungals occur also among closely related fungal species. Up to $20 \%$ of the strains of Candida glabrata are intrinsically resistant to azoles and even susceptible strains can quickly acquire resistance, leading doctors to recommend echinocandins as a first line therapy to treat a range of candidiasis [46,47]. Furthermore, it is not understood exactly how Cryptococcus neoformas can tolerate echinocandin concentrations that are generally inhibitory, given that the enzyme target $(1,3)$-Beta-D-Glucan synthase is highly inhibited by echinocandins in vitro, suggesting that the resistance mechanism would not be linked to the enzyme [48]. 
The phenomenon of hetero-resistance is another example of variation in drug susceptibility within a population. For example, individual cells of Cryptococcus and Candida albicans are able of developing a progeny with phenotypes of heterogeneous resistance, with a small subset of the progeny with azole resistance [49-51]. This phenomenon allows to populations adapt to increasing concentrations of azoles in a gradual manner, restoring the original susceptibility after fungal cells are no exposed to antifungal drugs [50]. The molecular mechanism that governs this response in C. neoformans involves the acquisition of a disomy on chromosome 1, which shares the genes for the azole target ERG11 and the efflux transporter AFR1 [52]. Such phenomena have been observed in clinical and laboratory settings $[50,53]$, which represents an intrinsic adaptive mechanism for survival during azole stress.

On the other hand, antifungal resistance has become a significant concern for clinicians who are responsible for caring for patients at high risk of suffering from invasive fungal infections. Resistance to current antifungal agents may develop secondary mechanisms of resistance acquisition once patients are exposed to these drugs. Recent trends in acquired antifungal resistance include increased resistance to azoles between non-Candida albicans and Aspergillus fumigatus isolates, and resistance to echinocandins in C. glabrata [5458]. In contrast, some fungal species are intrinsically resistant to certain antifungal drugs (eg C. kuresi to fluconazole, or C. lusitaniae to amphotericin $\mathrm{B}$ ), while others have demonstrated microbial resistance to all clinically available antifungal drugs (eg Lomentospora prolificans and Fusarium solani) [59-61]. However, new species of fungi resistant to multiple available drugs (eg C.

\section{Conclusion}

In this review, we exposed some aspects about antifungal resistance mechanisms and role of evolution in acquisition of resistance. Although the prevalence of antifungal resistance does not occur at the levels observed for some bacteria against different antibiotics, treatment options for invasive fungal infections are limited, and high-risk patients often have multiple co-morbidities, among which are included immunosuppression, which may limit the effectiveness of the therapy, even in the absence of resistance to antifungal drugs. In consequence, new treatment strategies are required to mitigate these resistances, and also overcome the adverse effects and toxicity, as well as drug interactions that are associated with current available antifungals, which may limit the effectiveness of the therapy.

\section{References}

1. McNeil MM, Nash SL, Hajjeh RA, Phelan MA, Conn LA, et al. (2001) Trends in Mortality Due to Invasive Mycotic Diseases in the United States, 1980-1997. Clin Infect Dis 33(5): 641-647.

2. Srinivasan A, Lopez-Ribot JL, Ramasubramanian AK (2014) Overcoming antifungal resistance. Drug Discov Today Technol 65-71.
3. Perlin DS (2015) Echinocandin Resistance in Candida. Clin Infect Dis 61(Suppl 6): S612-S617.

4. Pfaller MA, Messer SA, Moet GJ, Jones RN, Castanheira M (2011) Candida bloodstream infections: comparison of species distribution and resistance to echinocandin and azole antifungal agents in Intensive Care Unit (ICU) and non-ICU settings in the SENTRY Antimicrobial Surveillance Program (2008-2009). Int J Antimicrob Agents 38(1): 6569.

5. Cortés JA, Reyes P, Gómez CH, Cuervo SI, Rivas P, et al. (2014) Clinical and epidemiological characteristics and risk factors for mortality in patients with candidemia in hospitals from Bogotá, Colombia. Braz J Infect Dis 18(6): 631-637.

6. Sanglard D, Coste AT (2015) Activity of Isavuconazole and Other Azoles against Candida Clinical Isolates and Yeast Model Systems with Known Azole Resistance Mechanisms. Antimicrob Agents Chemother 60(1): 229-238.

7. Sanglard D (2016) Emerging Threats in Antifungal-Resistant Fungal Pathogens. Send to Front Med (Lausanne) 3: 11.

8. Pfaller MA, Diekema DJ (2010) Epidemiology of Invasive Mycoses in North America. Crit Rev Microbiol 36(1): 1-53.

9. Chassot F, Venturini TP, Piasentin FB, Rossato L, Fiorini A, et al. (2016) Exploring the In Vitro Resistance of Candida parapsilosis to Echinocandins. Mycopathologia 181(9-10): 663-670.

10. Chowdhary A, Anil Kumar V, Sharma C, Prakash A, Agarwal K, et al. (2014) Multidrug-resistant endemic clonal strain of Candida auris in India. Eur J Clin Microbiol Infect Dis 33(6): 919-926.

11. Calvo B, Melo ASA, Perozo-Mena A, Hernandez M, Francisco EC, et al. (2016) First report of Candida auris in America: Clinical and microbiological aspects of 18 episodes of candidemia. J Infect 73(4): 369-374.

12. Wiederhold NP (2017) Antifungal resistance: current trends and future strategies to combat. Infect Drug Resist 10 249-259.

13. Araujo R, Pina-Vaz C, Rodrigues AG (2007) Susceptibility of environmental versus clinical strains of pathogenic Aspergillus. Int J Antimicrob Agents 29(1): 108-111.

14. Blum G, Hörtnagl C, Jukic E, Erbeznik T, Pümpel T, et al. (2013) New Insight into Amphotericin B Resistance in Aspergillus terreus. Antimicrobial Agents and Chemotherapy 57(4): 1583-1588.

15. Brown GD, Denning DW, Gow NAR, Levitz SM, Netea MG, et al. (2012) Hidden Killers: Human Fungal Infections. Sci Transl Med 4(165): $165 \mathrm{rv} 13$.

16. Denning DW (2003) Echinocandin antifungal drugs. Lancet 362(9390): 1142-1151.

17. Kanafani ZA, Perfect JR (2008) Resistance to Antifungal Agents: Mechanisms and Clinical Impact. Clinical Infectious Diseases 46(1): 120-128.

18. Alcazar-Fuoli L, Mellado E (2014) Current status of antifungal resistance and its impact on clinical practice. Br J Haematol 166(4): 471-484.

19. Cowen LE, Sanglard D, Howard SJ, Rogers PD, Perlin DS (2015) Mechanisms of Antifungal Drug Resistance. Cold Spring Harb Perspect Med 5(7): a019752.

20. Scorzoni L, de Paula e Silva ACA, Marcos CM, Assato PA, de Melo WCMA, et al. (2017) Antifungal Therapy: New Advances in the Understanding and Treatment of Mycosis. Front Microbiol 8: 36.

21. Ramage G, Saville SP, Thomas DP, Lopez-Ribot JL (2005) Candida Biofilms: an Update. Eukaryot Cell 4(4): 633-638. 


\section{Advances in Biotechnology \& Microbiology}

22. Mitchell KF, Zarnowski R, Sanchez H, Edward JA, Reinicke EL, et al (2015) Community participation in biofilm matrix assembly and function. Proc Natl Acad Sci 112(13): 4092-4097.

23. Silva S, Rodrigues C, Araújo D, Rodrigues M, Henriques M (2017) Candida Species Biofilms' Antifungal Resistance. J Fungi 3(1): 8.

24. Bonhomme J, D’Enfert C (2013) Candida albicans biofilms: building a heterogeneous, drug-tolerant environment. Curr Opin Microbiol 16(4): 398-403.

25. Vediyappan G, Rossignol T, D’Enfert C (2010) Interaction of Candida albicans Biofilms with Antifungals: Transcriptional Response and Binding of Antifungals to Beta-Glucans. Antimicrob. Agents Chemother 54(5): 2096-2111.

26. Berkow E, Lockhart S (2017) Fluconazole resistance in Candida species: a current perspective. Infect Drug Resist 10: 237-245.

27. Lamb DC, Kelly DE, White TC, Kelly SL (2000) The R467K amino acid substitution in Candida albicans sterol 14alpha-demethylase causes drug resistance through reduced affinity. Antimicrob Agents Chemother 44(1): 63-67.

28. Kelly SL, Lamb DC, Corran AJ, Baldwin BC, Kelly DE (1995) Mode of Action and Resistance to Azole Antifungals Associated with the Formation of $14 \alpha$-Methylergosta-8,24(28)-dien-3 $\beta, 6 \alpha$-diol. Biochem Biophys Res Commun 207(3): 910-915.

29. Chau AS, Gurnani M, Hawkinson R, Laverdiere M, Cacciapuoti A, et al. (2005) Inactivation of Sterol 5,6-Desaturase Attenuates Virulence in Candida albicans. Antimicrob Agents Chemother 49(9): 3646-3651.

30. Eddouzi J, Parker JE, Vale-Silva LA, Coste A, Ischer F, et al. (2013) Molecular Mechanisms of Drug Resistance in Clinical Candida Species Isolated from Tunisian Hospitals. Antimicrob Agents Chemother 57(7): 3182-3193.

31. Martel CM, Parker JE, Bader O, Weig M, Gross U, et al. (2010) Identification and Characterization of Four Azole-Resistant erg3 Mutants of Candida albicans. Antimicrob Agents Chemother 54(11): 4527-4533.

32. Morio F, Pagniez F, Lacroix C, Miegeville M, Le Pape P (2012) Amino acid substitutions in the Candida albicans sterol 5,6-desaturase (Erg3p) confer azole resistance: characterization of two novel mutants with impaired virulence. J Antimicrob Chemother 67(9): 2131-2138.

33. Anderson TM, Clay MC, Cioffi AG, Diaz KA, Hisao GS, et al. (2014) Amphotericin forms an extramembranous and fungicidal sterol sponge. Nat Chem Biol 10(5): 400-406.

34. Jensen-Pergakes KL, Kennedy MA, Lees ND, Barbuch R, Koegel C, et al. (1998) Sequencing, disruption, and characterization of the Candida albicans sterol methyltransferase (ERG6) gene: drug susceptibility studies in erg6 mutants. Antimicrob Agents Chemother 42(5): 1160 1167.

35. Jia N, Arthington-Skaggs B, Lee W, Pierson CA, Lees ND, et al. (2002) Candida albicans Sterol C-14 Reductase, Encoded by the ERG24 Gene, as a Potential Antifungal Target Site. Antimicrob Agents Chemother 46(4): 947-957.

36. Vincent BM, Lancaster AK, Scherz-Shouval R, Whitesell L, Lindquist S (2013) Fitness Trade-offs Restrict the Evolution of Resistance to Amphotericin B. PLoS Biol 11(10): e1001692.

37. Dodgson AR, Dodgson KJ, Pujol C, Pfaller MA, Soll DR (2004) CladeSpecific Flucytosine Resistance Is Due to a Single Nucleotide Change in the FUR1 Gene of Candida albicans. Antimicrob Agents Chemother 48(6): 2223-2227.

38. Shapiro RS, Robbins N, Cowen LE (2011) Regulatory Circuitry Governing Fungal Development, Drug Resistance, and Disease Microbiol Mol Biol Rev 75(2): 213-267.
39. D'Costa VM, King CE, Kalan L, Morar M, Sung WWL, et al. (2011) Antibiotic resistance is ancient. Nature 477(7365): 457-461.

40. Wright GD, Poinar $\mathrm{H}$ (2012) Antibiotic resistance is ancient: implications for drug discovery. Trends Microbiol 20(4): 157-159.

41. Cowen LE, Steinbach WJ (2008) Stress, Drugs, and Evolution: the Role of Cellular Signaling in Fungal Drug Resistance. Eukaryot Cell 7(5): 747-764.

42. Robbins N, Wright GD, Cowen LE (2016) Antifungal Drugs: The Current Armamentarium and Development of New Agents. Microbiol spectr 4(5): 903-922.

43. Anderson JB (2005) Evolution of antifungal-drug resistance: mechanisms and pathogen fitness. Nat Rev Microbiol 3(7): 547-556.

44. Stevens DA, Ichinomiya M, Koshi Y, Horiuchi H (2006) Escape of Candida from Caspofungin Inhibition at Concentrations above the MIC (Paradoxical Effect) Accomplished by Increased Cell Wall Chitin; Evidence for -1,6-Glucan Synthesis Inhibition by Caspofungin. Antimicrob Agents Chemother 50(9): 3160-3161.

45. Wiederhold NP (2007) Attenuation of echinocandin activity at elevated concentrations: a review of the paradoxical effect. Curr Opin Infect Dis 20(6): 574-578

46. Pappas PG, Kauffman CA, Andes DR, Clancy CJ, Marr KA, et al. (2016) Clinical Practice Guideline for the Management of Candidiasis: 2016 Update by the Infectious Diseases Society of America. Clin Infect Dis 62(4): e1-50.

47. Chang CC, Slavin MA, Chen SC-A (2017) New developments and directions in the clinical application of the echinocandins. Arch Toxicol 91(4): 1613-1621.

48. Maligie MA, Selitrennikoff CP (2005) Cryptococcus neoformans Resistance to Echinocandins: (1,3) -Glucan Synthase Activity Is Sensitive to Echinocandins. Antimicrob. Agents Chemother 49(7): 2851-2856.

49. Calvet HM, Yeaman MR, Filler SG (1997) Reversible fluconazole resistance in Candida albicans: a potential in vitro model. Antimicrob Agents Chemother 41(3): 535-539.

50.Sionov E, Chang YC, Garraffo HM, Kwon-Chung KJ (2009) Heteroresistance to Fluconazole in Cryptococcus neoformans Is Intrinsic and Associated with Virulence. Antimicrob Agents Chemother 53(7): 2804-2815.

51. Varma A, Kwon-Chung KJ (2010) Heteroresistance of Cryptococcus gattii to Fluconazole. Antimicrob Agents Chemother 54(6): 2303-2311.

52. Sionov E, Lee H, Chang YC, Kwon-Chung KJ (2010) Cryptococcus neoformans overcomes stress of azole drugs by formation of disomy in specific multiple chromosomes. PLoS Pathog 6(4): e1000848.

53. Sionov E, Chang YC, Kwon-Chung KJ (2013) Azole Heteroresistance in Cryptococcus neoformans: Emergence of Resistant Clones with Chromosomal Disomy in the Mouse Brain during Fluconazole Treatment. Antimicrob Agents Chemother 57(10): 5127-5130.

54. Healey KR, Jimenez Ortigosa C, Shor E, Perlin DS (2016) Genetic Drivers of Multidrug Resistance in Candida glabrata. Front Microbiol 7.

55. Chowdhary A, Sharma C, Kathuria S, Hagen F, Meis JF (2014) Azoleresistant Aspergillus fumigatus with the environmental TR46/Y121F/ T289A mutation in India. J Antimicrob Chemother 69(2): 555-557.

56. Chowdhary A, Sharma C, Hagen F, Meis JF (2014) Exploring azole antifungal drug resistance in Aspergillus fumigatus with special reference to resistance mechanisms. Future Microbiol 9(5): 697-711.

57. Verweij PE, Chowdhary A, Melchers WJ, Meis JF (2016) Azole Resistance in Aspergillus fumigatus : Can We Retain the Clinical Use of Mold-Active Antifungal Azoles? Clin Infect Dis 62(3): 362-368. 
58. Rivero-Menendez 0, Alastruey-Izquierdo A, Mellado E, Cuenca-Estrella M (2016) Triazole Resistance in Aspergillus spp.: A Worldwide Problem? J Fungi 2(3): E21.

59. Lackner M, De Hoog GS, Yang L, Ferreira Moreno L, Ahmed SA, et al. (2014) Proposed nomenclature for Pseudallescheria, Scedosporium and related genera. Fungal Diversity 67(1): 1-10.

60. Lackner M, Hagen F, Meis JF, Gerrits van den Ende AHG, Vu D, Robert V, et al. (2014) Susceptibility and Diversity in the Therapy-Refractory Genus Scedosporium. Antimicrobial Agents and Chemotherpy 58(10): 5877-5885.
61. Walsh TJ, Groll A, Hiemenz J, Fleming R, Roilides E, et al. (2004) Infections due to emerging and uncommon medically important fungal pathogens. Clin Microbiol Infect Suppl 1: 48-66.

62. Lockhart SR, Etienne KA, Vallabhaneni S, Farooqi J, Chowdhary A, et al. (2017) Simultaneous Emergence of Multidrug-Resistant Candida auris on 3 Continents Confirmed by Whole-Genome Sequencing and Epidemiological Analyses. Clin Infect Dis 64(2): 134-140.

\section{Your next submission with Juniper Publishers will reach you the below assets}

- Quality Editorial service

- Swift Peer Review

- Reprints availability

- E-prints Service

- Manuscript Podcast for convenient understanding

- Global attainment for your research

- Manuscript accessibility in different formats ( Pdf, E-pub, Full Text, Audio)

- Unceasing customer service

Track the below URL for one-step submission https://juniperpublishers.com/online-submission.php 